\title{
A nationally representative survey of hospital malnutrition: the Italian PIMAI (Project: Iatrogenic MAlnutrition in Italy) study
}

\author{
Lucio Lucchin • Amleto D'Amicis • Maria Gabriella Gentile • Nino Carlo Battistini • \\ Maria Antonia Fusco • Augusta Palmo • Maurizio Muscaritoli • Franco Contaldo • \\ Emanuele Cereda and the PIMAI group
}

Received: 3 March 2009 / Accepted: 11 May 2009 / Published online: 8 July 2009

(c) Springer-Verlag 2009

\begin{abstract}
Hospital malnutrition is high in every country it was investigated, but no nationally representative prevalence study, considering potential geographical interfering factors, has yet been performed. We designed a multidisciplinary, cross-sectional, nation-wide survey: the PIMAI study (Project: Iatrogenic MAlnutrition in Italy). Adult ( $>18$ years old) patient inclusion was managed on a four-strata randomisation model according to sex and age (<65 and $\geq 65$ years). Malnutrition was defined by analytical criteria related to recent food intake and both physical (body mass index, weight loss, midupper arm anthropometry) and biochemical (albumin, prealbumin and lymphocyte count) malnutrition correlates. Thirteen hospitals ( $n=1583$ ) completed the study. The survey is likely to represent the country of Italy.
\end{abstract}

Statement of authorship All the authors significantly contributed to the work, read and approved the final manuscript. LL, AD, MGG, NCB and MAF designed the study. AD and EC analysed data. EC wrote the manuscript. All the Authors contributed to data interpretation and critical revision of the article.

\author{
E. Cereda (西) \\ International Center for the Assessment of Nutritional Status \\ Università degli Studi di Milano \\ Via Botticelli 21 \\ 20133 Milan, Italy \\ e-mail: emanuele.cereda@virgilio.it
}

*See the end of the text for the complete list of affiliations
Overall prevalence of malnutrition was $30.7 \%$, with higher rates in the northern macroarea $(36.7 \%)$ than in central $(28.0 \%)$, southern $(26.9 \%)$ and island $(16.7 \%)$ ones $(p<0.0001)$. This discrepancy appeared to be mainly related to the prevalence of overweight/obesity. By a multivariate model, malnutrition was significantly lower in males $(p<0.05)$ and surgical wards $(p<0.002)$, associated with geography $(p<0.05)$ and consistently higher in patients aged $\geq 65$ years $(p<0.01)$, presenting with malignancies $(p<0.005)$ and having multidrug therapy $(p<0.05)$. The prevalence of hospital malnutrition is high also in Italy. It presents with different geographical distribution also according to overweight prevalence. This evidence should be considered when designing national nutritional policies.

Keywords Hospital malnutrition . Prevalence . Nutritional assessment $\cdot$ Nutritional status $\cdot$ Nationwide survey $\cdot$ Multidisciplinary

\section{Introduction}

The prevalence of protein-energy malnutrition among hospitalised patients, which turns out to be high in every country, has frequently been investigated [1], ranging between $20 \%$ and $50 \%$ in those newly admitted, depending on age, discipline (medical, surgical or intensive care) and specialties considered, sensitivity and specificity of definition criteria as well as study sample size [1-5].

The clinical and economic relevance of malnutrition parallels its frequency. The hospital stay is lengthened, while morbidity and mortality, particularly among the elderly, as well as the cost of care are consistently 
increased [1-10]. Moreover, more than 20 years have passed since worsening of nutritional status (e.g., by weight loss) during hospital stay was first reported [11].

Unfortunately, despite increasing awareness of "the malnutrition problem" and its consequences, recent insights into current clinical practice reveal poor nutritional routines and attitudes among doctors and nurses [12-14].

All these findings prompted the European Council to first set up a Study Group on the matter and to successively issue a Resolution to improve the knowledge of and enforce actions to combat this problem, focusing attention on the screening process and treatment through nutritional support and normal hospital diet [15]. In this regard, obtaining information on the actual dimension of the problem and associated factors is the first step in designing and applying nutritional policies. Unfortunately, up to now, few studies have been performed that have aimed to be both nationally representative and multidisciplinary $[9$, 16-18]. Nevertheless, there is evidence that diseases might present with different geographical distribution and data obtained from studies considering this effect too are generally more applicable [5, 18, 19]. Moreover, scant and unreliable data on the Italian state of art are now available [20]. According to this background the Federation of Nutritional Italian Societies (FeSIN) designed the multicentric "PIMAI study" (Project: Iatrogenic MAlnutrition in Italy) in order to: (1) estimate the national prevalence of malnutrition among Italian hospital in-patients and (2) investigate potential geographical differences and factors that should be considered when designing national nutritional policies.

\section{Methods}

Study design and Ethical Committee approval

The study protocol, in adherence to the principles established by the Declaration of Helsinki, was drafted and firstly approved by the Ethical Committee of the coordinating Centre (Regional General Hospital of Bolzano, Italy) and subsequently approved by the local committees of each participating centre. Every conscious patient, or caregiver for those unconscious, was asked for their informed consent.

The design was a 10-month (from 1 December 2004 to 15 September 2005) nationally representative survey aimed to reliably estimate the prevalence of malnutrition in Italian hospitals $(n=746)$. Among those with more than 400 beds $(n=186)$, we selected 20 structures, one for every single region of Italy, with recognised engagement in the field of malnutrition (presence of a clinical nutrition unit and equipe).
Survey standardisation

In order to standardise operating methodology and reduce intra- and inter-individual errors, we organised four 8-h courses (frontal lessons plus practical working sessions in small groups), one for each of the four macroareas of the country (North-East, North-West, Centre and South plus Island).

All the Centres participating in the survey received an identical calibrated technical-instrumental kit, which was used for all the measurements. The kit included: an electronic class-III scale (SECA 861, SECA, Hamburg, Germany), a steel flexible metric tape, a portable telescopic stadiometer (Telefix, Metrica, Italy), a Holtain skinfold caliper (Holtain Ltd., Crymych, UK) and a Harpenden anthropometer (DS Medigroup, Milan, Italy).

It was planned that each hospital should enrol and question no more than 3 patients/day, randomly selected from the daily list of new admissions, up to a total of $100-150$. Random sampling was further managed on a 4strata model according to sex (male and female) and age ( $<65$ and $\geq 65$ years). Paediatric (age $<18$ years), pregnant and acute emergency patients were excluded. Finally, it was established that every patient included should be assessed within $36 \mathrm{~h}$ of admission.

Nutritional assessment variables

\section{Anthropometric measurements}

- Body weight (to the nearest $0.1 \mathrm{~kg}$ ): by the same calibrated scale, with the subject fasted and wearing only underwear. For those bedridden or unable to stand in an erect position, a hoist provided weighing device or a chair scale were used, respectively.

- History of recent (1-month previous) unintentional weight loss 5\% was obtained by anamnestic recall whenever possible; those reporting "not known" were not counted in the analyses.

- Body height (to the nearest $0.1 \mathrm{~cm}$ ): by the same telescopic stadiometer, with the subject in erect stretched position, the feet well positioned and the head held in the Frankfurt plane. In case the height could not be measured directly the knee-heel length was used as a proxy indicator for estimation.

- Body mass index (BMI) was accordingly calculated as weight $(\mathrm{kg}) / \mathrm{height}(\mathrm{m})^{2}$.

- Mid-upper anthropometry, measured on the non-dominant arm according to standard procedures, included arm circumference (AC; to the nearest $0.1 \mathrm{~cm}$ ) and triceps skinfold thickness (TSF; to the nearest 0.1 
cm). Arm muscle area (AMA) was accordingly calculated by a validated formula. AC, TSF and AMA values were then compared to reference standards currently in use [21].

\section{Biochemical parameters}

Venous blood samples were drawn the day after admission after an 8 to 12-h fast and assessed for serum albumin, prealbumin and total lymphocyte count (TLC).

\section{Oral intake}

Simple dietary assessment was performed by well trained dieticians and consisted in the semiquantitative evaluation of oral intake during the 1-week period before admission and a cross-validation through a 24-h dietary recall. Then, oral intake was defined as the percentage of food consumed compared to normal habits (average weight or size of the portions of main courses, side dishes, bread and surrogates, fruit, snacks, cakes). Accordingly, categorisation in quartiles $(0-\leq 25 \%$; $25-\leq 50 \% ; 50-\leq 75 \%$; $>75 \%$ ) was performed.

\section{Definition of malnutrition}

Although many simplified tools for nutritional screening are now available, and among them the use of Nutritional Risk Screening 2002 (NRS-2002) and Malnutrition Universal Screening Tool (MUST) is enforced [4, 5, 22-24], we decided to define risk of malnutrition by simple-to-collect analytical criteria based on critical interpretation of the existing literature.

1. $\mathrm{BMI}<18.5 \mathrm{~kg} / \mathrm{m}^{2}$

2. $18.5 \leq \mathrm{BMI}<20+$ at least 1 indicator $\mathrm{A}$

3. 1-month previous weight loss $\geq 5 \%+$ at least 1 indicator B

4. 2 or more indicators $A$

A: weight loss $\geq 5 \%$, albumin $<35 \mathrm{~g} / \mathrm{l}$, prealbumin $<15$ $\mathrm{mg} / \mathrm{dl}$, AMA $<25$ th percentile, triceps skinfold $<$ 25 th percentile, TLC $<1500 / \mathrm{mm}^{3}$, oral intake $\leq 50 \%$ of normal habits.

B: albumin $<35 \mathrm{~g} / \mathrm{l}$, prealbumin $<15 \mathrm{mg} / \mathrm{dl}$, AMA $<$ 25 th percentile, triceps skinfold $<25$ th percentile, TLC $<1500 / \mathrm{mm}^{3}$, oral intake $\leq 50 \%$ of normal habits.

This choice was made on the basis of a number of major considerations. First, the choice of these criteria would theoretically allow identification of all malnourished patients regardless of possible missing values, which is clearly an advantage in clinical practice and nutritional assessment. In both NRS-2002 and MUST, weight loss and status (by BMI) play a key role but they are sometimes unavailable or difficult to obtain (e.g., in the elderly or unconscious patients). Along with this, a consistent number of prevalence studies have usually considered similar criteria (for the overall list of surveys see the recent review by Norman et al.) [1] rather than multidimensional screening tools. Moreover, in those investigations reporting estimates by these scoring systems, the Subjective Global Assessment (SGA), whose use is suggested to detect overt malnutrition and whose results are primarily based on physical signs of malnutrition, was the most frequently chosen [9, 17-19, 25]. Finally, the recent comparison of screening tools at hospital admission by Kyle et al. [4], supports the agreement between the SGA classes and risk scores by NRS-2002 and MUST. Accordingly, we believed that our data would be comparable to the others previously reported.

\section{Risk factors for malnutrition}

Apart from age and gender, which were considered for random selection of patients during study design (4strata model), the presence of malignancies (cancer) was considered as a major risk factor for malnutrition. Along with this, number of prescriptions per day (drugs/day) was taken as a surrogate of disease severity and presence of comorbidities. Accordingly, patients were stratified as follows: 0-2 drugs/day, 3-5 drugs/day, $\geq 6$ drugs/day.

Data management and analysis

Each participating Centre produced an electronic archive that was then sent to the Analysis Unit at the National Institute for Research on Food and Nutrition (INRAN). Data were first checked for completeness and then analysed (STATA 9 Statistical Software, StataCorp LP, College Station, TX, USA). Data are described as mean, standard deviation or absolute frequencies. Comparison between groups were performed by an unpaired $t$-test or ANOVA analysis, followed by Scheffe's test (post hoc comparison of means) or chisquare $\left(\chi^{2}\right)$ test where appropriate. Finally, logistic regression analysis was used to assess independent variables associated with malnutrition and to calculate odds ratios with $95 \%$ confidence intervals (95\% CI). For overall analyses, statistical significance was set to a $p$ value $<0.05$. 


\section{Results}

In the study design it was planned to include 20 hospitals, representative of the 20 Italian regions. Seven hospitals/regions refused to participate due to difficulties in allowing the necessary personnel for all the study period (training and/or data collection) or delay of approval by the local ethical committee. In spite of this, and according to the distribution of the Italian population [26], the remaining structures included $(n=13)$ were representative of the northern, central, southern and island parts of the country (Fig. 1, Table 1).

In total, 1830 patients fulfilled the inclusion criteria. Of these, $234(14.6 \%)$ refused to participate and 13 $(0.7 \%)$ were further excluded due to terminal illness. Accordingly, final data analysis was performed on a study sample of 1583 subjects. Possible missing values are reported where appropriate.

Patients were recruited from all the possible specialties but most of them were from general medicine (20.3\%) and surgery $(12.7 \%)$. In overall population analyses, subjects admitted to Intensive Care Units where arbitrarily considered among surgical because of the similarities between critical illness and surgical stress and the relative possible effects on nutritional status. Distribution of patients according to 4-strata model random selection by sex (male and female) and age ( $<65$ and $\geq 65$ years) is presented in Table 2. Overall country prevalence of malnutrition (Table 2) was $30.7 \%(n=486)$, with significantly higher rates in the northern macroarea $(36.7 \%, n=266)$ rather than in central

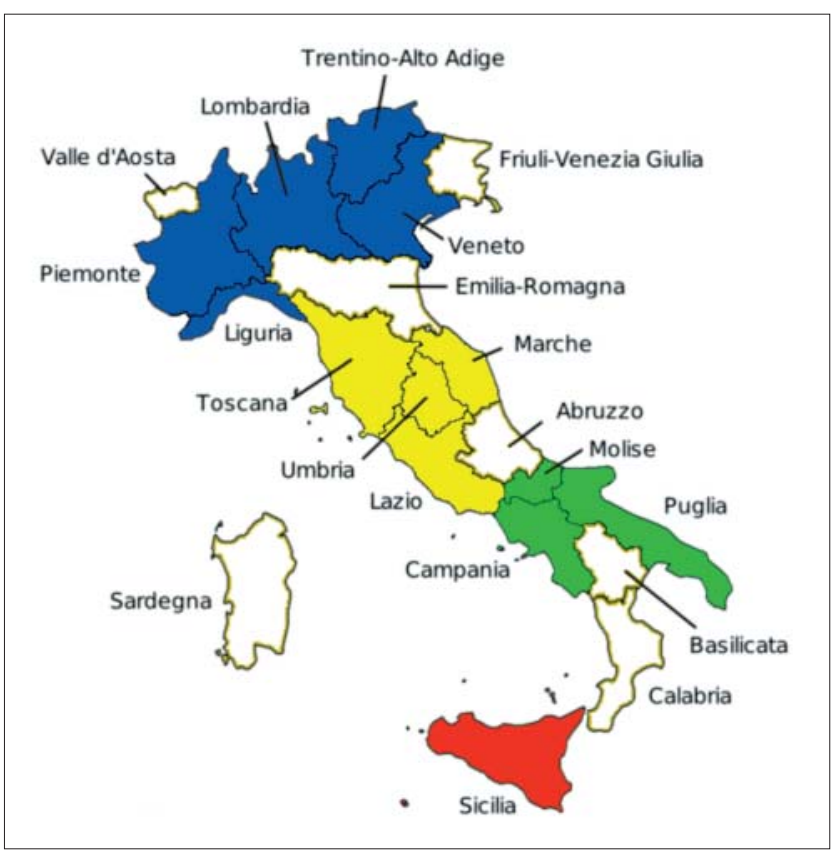

Fig. 1 Regions excluded from (white) and included in the study according to Italian macroareas (north, centre, south, island: coloured)
Table 1 Number and percentage of patients enrolled in Italian macroareas (and regions) compared with the population's distribution in whole country. Total number of patients $n=1583$

\begin{tabular}{llll}
\hline & Study sample & $\begin{array}{l}\text { Italian macroareas } \\
\text { population*, \% }\end{array}$ \\
\cline { 2 - 3 } & $n$ & $\%$ & \\
\hline North & 725 & 45.8 & 45.4 \\
Liguria & 141 & 8.9 & \\
Lombardy & 150 & 9.4 & \\
Piedmont & 132 & 8.3 & \\
Trentino Alto- & 151 & 9.5 & \\
Adige & & & \\
Veneto & 151 & 9.5 & 21.7 \\
Centre & 343 & 21.7 & \\
Lazio & 26 & 1.6 & \\
Marche & 90 & 5.7 & \\
Tuscany & 150 & 9.5 & \\
Umbria & 77 & 4.8 & 21.6 \\
South & 371 & 23.4 & \\
Campania & 150 & 9.5 & \\
Molise & 100 & 6.3 & \\
Puglia & 121 & 7.6 & \multirow{2}{*}{11.3} \\
Islands & 144 & 9.1 & \\
Sicily & 144 & 9.1 & \\
\hline
\end{tabular}

*Prevalence reported refers to data by the Italian National Institute of Statistics [26]

(28.0\%, $n=96)$, southern $(26.9 \%, n=100)$ and island $(16.7 \%, n=24)$ ones $\left(\chi^{2}=29.19, p<0.0001\right)$. The discrepancy detected was mainly related to the high prevalence of overweight and obese subjects recruited, particularly in the southern and island macroareas $\left(\chi^{2}=28.27, p<0.001\right.$; Table 3), data that reliably reflect the trends of the Italian demography [26, 27]. In fact, when counting for malnutrition according to weight status (underweight, normalweight, overweight and obesity) and macroareas, no significant differences were observed in prevalence $\left(\chi^{2}=13.29\right.$, $p=0.1499)$. Along with this, we underscore that malnutrition was mainly diagnosed by a low BMI $\left(<20 \mathrm{~kg} / \mathrm{m}^{2}\right)$ in only 107 patients $(22 \%)$ while for the others $(n=379,78 \%)$ the use of further analytic criteria was fundamental (Table 2). Higher rates of malnutrition were also observed in the medical vs. surgical wards $(37.0 \%$ vs. $23.3 \%$ respectively; $\left.\chi^{2}=35.00, p<0.0001\right)$, in women vs. men $(33.3 \% v s$. $\left.28.0 \% ; \chi^{2}=5.20, p=0.0226\right)$, in those aged $\geq 65$ years (34.3\% vs. $27.7 \% ; \chi^{2}=8.26, p=0.0041$; Tables 2 and 4 ) and in patients suffering from malignancies $(40.8 \%$ of total $n=240$ ). According to specialty, prevalence of malnutrition was markedly heterogeneous, raging between $4.3 \%$ (ophthalmology) and 59\% (geriatrics) and with consistently higher rates in other medical patients, particularly those affected by gastrointestinal $(56.7 \%)$, infective $(55.8 \%)$, respiratory $(45.0 \%)$ diseases and in oncology units $(43.3 \%)$.

Clinical features of malnourished patients admitted to medical and surgical wards are presented in Table 4. Interestingly, malnourished patients in medical departments 
Table 2 Prevalence of malnutrition according to analytical criteria and stratification by sex and age

\begin{tabular}{|c|c|c|c|c|c|c|}
\hline \multirow[t]{2}{*}{ Criteria } & \multicolumn{2}{|c|}{ Women $(n=795)$} & \multicolumn{2}{|c|}{$\operatorname{Men}(n=788)$} & \multicolumn{2}{|c|}{ Population $(n=1583)$} \\
\hline & $\begin{array}{l}<65 \text { years } \\
(n=426)\end{array}$ & $\begin{array}{l}\geq 65 \text { years } \\
(n=369)\end{array}$ & $\begin{array}{l}<65 \text { years } \\
(n=438)\end{array}$ & $\begin{array}{l}\geq 65 \text { years } \\
(n=350)\end{array}$ & $\begin{array}{l}<65 \text { years } \\
(n=864)\end{array}$ & $\begin{array}{l}\geq 65 \text { years } \\
(n=719)\end{array}$ \\
\hline $\mathrm{BMI}<18.5 \mathrm{~kg} / \mathrm{m}^{2}$ & $17(3.9 \%)$ & $12(3.3 \%)$ & $10(2.3 \%)$ & $7(2.0 \%)$ & $27(3.1 \%)$ & $19(2.6 \%)$ \\
\hline $\begin{array}{l}18.5 \leq \mathrm{BMI}<20 \\
+ \text { at least } 1 \text { indicator } \mathrm{A}\end{array}$ & $24(5.6 \%)$ & $10(2.7 \%)$ & $16(3.6 \%)$ & $11(3.1 \%)$ & $40(4.7 \%)$ & $21(2.9 \%)$ \\
\hline $\begin{array}{l}\text { Weight loss } \geq 5 \% \\
+ \text { at least } 1 \text { indicator } B\end{array}$ & $19(4.6 \%)$ & $33(8.9 \%)$ & $31(7.1 \%)$ & $30(8.6 \%)$ & $50(5.8 \%)$ & $63(8.8 \%)$ \\
\hline 2 or more indicators $\mathrm{A}$ & $70(16.4 \%)$ & $80(21.7 \%)$ & $52(11.9 \%)$ & $64(18.3 \%)$ & $122(14.1 \%)$ & $144(20.0 \%)$ \\
\hline \multicolumn{7}{|l|}{ Malnutrition } \\
\hline Prevalence by age & $130(30.5 \%)$ & $135(36.6 \%)$ & $109(24.9 \%)$ & $112(32.0 \%)^{*}$ & $239(27.7 \%)$ & $247(34.3 \%) \dagger$ \\
\hline Overall prevalence & $33.3 \%$ & & $28.0 \% \ddagger$ & & $30.7 \%$ & \\
\hline
\end{tabular}

$A$ weight loss $\geq 5 \%$ in the last month or albumin $<35 \mathrm{~g} / \mathrm{l}$ or prealbumin $<15 \mathrm{mg} / \mathrm{dl}$ or AMA $<25$ th percentile or triceps skinfold $<25$ th percentile or TLC $<1500 / \mathrm{mm}^{3}$ or oral intake $\leq 50 \%$

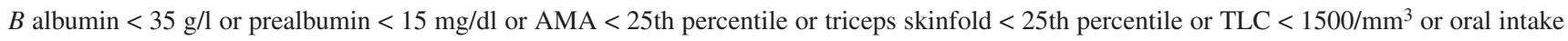
$\leq 50 \%$

$* p<0.03 ; \dagger p<0.005$ compared to subjects $<65$ years old by chi-square test

$\ddagger p<0.03$ compared to women by chi-square test

Table 3 Distribution of the population among body mass index (BMI) classes according to Italian macroareas

\begin{tabular}{|c|c|c|c|c|c|}
\hline & $\begin{array}{l}\text { North } \\
(n=699)\end{array}$ & $\begin{array}{l}\text { Centre } \\
(n=342)\end{array}$ & $\begin{array}{l}\text { South } \\
(n=313)\end{array}$ & $\begin{array}{l}\text { Island } \\
(n=126)\end{array}$ & $\begin{array}{l}\text { Overall country } \\
(n=1480)^{*}\end{array}$ \\
\hline Underweight, $\mathrm{BMI}<18.5 \mathrm{~kg} / \mathrm{m}^{2}$ & $35(5.0 \%)$ & $6(1.8 \%)$ & $5(1.6 \%)$ & $0(0 \%)$ & $46(3.1 \%)$ \\
\hline Normal weight, $18.5 \leq \mathrm{BMI}<25 \mathrm{~kg} / \mathrm{m}^{2}$ & $269(38.5 \%)$ & $148(43.3 \%)$ & $111(35.5 \%)$ & $38(30.2 \%)$ & $566(38.2 \%)$ \\
\hline Overweight, $25 \leq \mathrm{BMI}<30 \mathrm{~kg} / \mathrm{m}^{2}$ & $256(36.6 \%)$ & $126(36.8 \%)$ & $122(39.0 \%)$ & $53(42.1 \%)$ & $557(37.6 \%)$ \\
\hline Obesity, BMI $\geq 30 \mathrm{~kg} / \mathrm{m}^{2}$ & $139(19.9 \%)$ & $62(18.1 \%)$ & $75(24.0 \%)$ & $35(27.8 \%)$ & $311(21.0 \%)$ \\
\hline
\end{tabular}

*Prevalence data were reported according to missing values for BMI $(n=103)$. Overall chi-square $=28.27(p<0.001)$

were older $(p<0.0001)$ and had higher BMI $(p<0.005)$ and drug prescription $(p<0.002)$ than those in surgical wards. Moreover, presence of malignancies in surgical patients was more likely to be associated with poor nutritional status (25.3\% vs. $\left.17.4 \% ; \chi^{2}=4.27, p=0.0387\right)$.

Finally, we sought to identify independent risk factors associated with malnutrition at admission. In this regard, we initially performed a set of univariate logistic regressions. Accordingly, correlations were analysed through a multivariate model (Table 5). Female and people aged $\geq 65$ years were more likely to be malnourished $(p<0.05$ and $p$ $<0.01$, respectively). Significant associations were also found for those admitted to medical departments ( $p<$ $0.002)$, presenting with malignancies $(p<0.005)$ and characterised by more consistent pharmacological treatments $(p$ $<0.05)$. In addition, we underscored that overweight/obesity was clearly a protective factor $(p<0.0001)$ that consistently masked, but not completely, the signifi- cant association between malnutrition and data of country macroareas $(p<0.05)$ detected by the univariate model.

\section{Discussion}

The present study aimed to investigate the prevalence of hospital malnutrition in Italy. This is a further study, adding to the consistent number of those already performed in other countries $[1,2,5,9,11,16,17-19,25$, $28,29]$. However, it is the first study involving all hospital disciplines, aimed to be simultaneously nationally representative and able to suggest that geographical and demographic factors should also be considered when designing national health policies.

In fact, previous studies have more frequently considered Departments in which higher rates of admission and patients disease-related features are expected to negative- 
Table 4 Clinical variables of the study sample according to ward and nutritional status. Data are presented as mean \pm standard deviation or frequencies (gender, weight loss $\geq 5 \%$ in the last month and oral intake $\leq 50 \%$ ) and according to missing values [n]

\begin{tabular}{|c|c|c|c|c|c|}
\hline & \multirow[b]{2}{*}{$\begin{array}{l}\text { Overall } \\
(n=1583)\end{array}$} & \multicolumn{2}{|c|}{ Medical ward $(n=853)$} & \multicolumn{2}{|c|}{ Surgical ward $(n=730)$} \\
\hline & & $\begin{array}{l}\text { Malnourished } \\
(n=316)\end{array}$ & $\begin{array}{l}\text { Well nourished } \\
(n=537)\end{array}$ & $\begin{array}{l}\text { Malnourished } \\
(n=170)\end{array}$ & $\begin{array}{l}\text { Well nourished } \\
(n=560)\end{array}$ \\
\hline $\operatorname{Sex}(\mathrm{F} / \mathrm{M})$ & $795 / 788$ & $172 / 144 *$ & $252 / 285$ & $93 / 77$ & $278 / 282$ \\
\hline Age (years) & $59.2 \pm 17.9[1583]$ & $64.4 \pm 17.7[316]^{* \#}$ & $61.4 \pm 17.2[537]$ & $54.7 \pm 18.8[170]$ & $55.5 \pm 17.3[560]$ \\
\hline Body mass index $\left(\mathrm{kg} / \mathrm{m}^{2}\right)$ & $26.5 \pm 5.2[1480]$ & $23.9 \pm 4.8[290] \dagger \S$ & $28.2 \pm 5.0[499]$ & $22.6 \pm 4.0[162] \dagger$ & $27.4 \pm 4.8[529]$ \\
\hline Arm circumference $(\mathrm{cm})$ & $29.2 \pm 4.5[1570]$ & $25.9 \pm 4.1[316] \dagger$ & $30.8 \pm 4.2[529]$ & $25.8 \pm 3.9[170] \dagger$ & $30.5 \pm 3.7[555]$ \\
\hline Triceps skinfold (mm) & $16.4 \pm 7.8[1555]$ & $12.6 \pm 6.1[316] \dagger$ & $18.1 \pm 7.7[520]$ & $12.5 \pm 6.9[169] \dagger$ & $18.1 \pm 7.7[550]$ \\
\hline Arm muscle area $\left(\mathrm{cm}^{2}\right)$ & $46.6 \pm 14.1[1552]$ & $39.2 \pm 12.5[316] \dagger$ & $50.5 \pm 14.8[519]$ & $38.7 \pm 11.9[169] \dagger$ & $49.5 \pm 12.5[548]$ \\
\hline $\mathrm{WL} \geq 5 \%$ in the last month $(n)$ & 216 [1544] & $92[308] \dagger$ & 41 [524] & $46[166] \dagger$ & 37 [546] \\
\hline Albumin (g/l) & $40.5 \pm 8.7[1056]$ & $35.8 \pm 9.0[263] \dagger$ & $40.2 \pm 7.1[380]$ & $37.7 \pm 9.3[109] \dagger$ & $43.7 \pm 7.9[304]$ \\
\hline Prealbumin (mg/dl) & $22.8 \pm 9.2[336]$ & $17.5 \pm 8.6[90] \dagger$ & $25.4 \pm 9.2[101]$ & $20.2 \pm 8.8[38] \neq$ & $25.8 \pm 7.5[107]$ \\
\hline Total lymphocytes count $\left(/ \mathrm{mm}^{3}\right)$ & $1859 \pm 922[1327]$ & $1449 \pm 765[302] \dagger$ & $2011 \pm 999[456]$ & $1353 \pm 636[147] \dagger$ & $2166 \pm 845[422]$ \\
\hline Oral intake $\leq 50 \%(n)$ & 59 [1284] & $42[269]+4$ & 4 [419] & $10[142] \dagger$ & 3 [454] \\
\hline Malignancies $(n)$ & $240[1583]$ & $55[316] * \mathscr{I}$ & $61[537]$ & $43[170] \bullet$ & $81[560]$ \\
\hline Drugs $(n)$ & $2.6 \pm 2.6[1573]$ & $3.3 \pm 2.8[316] \S$ & $3.1 \pm 2.7[533]$ & $2.5 \pm 2.6[169] \neq$ & $1.7 \pm 2.1[555]$ \\
\hline
\end{tabular}

$W L$, weight loss

$* p<0.05 ; \bullet p<0.002 ; \ddagger p<0.0002 ; \dagger p<0.0001$ : compared to well nourished group within the same ward (by unpaired $t$-test or chi-square test) $\mathbb{I}[p<0.05 ; \S p<0.005 ; \# p<0.0001$ : compared to malnourished group in surgical ward (by unpaired $t$-test or chi-square test)

Table 5 Univariate and multivariate logistic regression models of independent risk factors for malnutrition. Analyses were performed according to missing values reported in Table 5 (multivariate model, $n=1472$ )

\begin{tabular}{|c|c|c|c|c|}
\hline \multirow[t]{2}{*}{ Risk factor } & \multicolumn{2}{|l|}{ Univariate model } & \multicolumn{2}{|c|}{ Multivariate model* } \\
\hline & OR $[95 \% \mathrm{CI}]$ & $p$ & OR $[95 \% \mathrm{CI}]$ & $p$ \\
\hline Gender (male vs. female) & $0.78[0.63-0.97]$ & 0.0226 & $0.7[0.60-1.00]$ & 0.0308 \\
\hline Age $\geq 65$ years & $1.37[1.10-1.70]$ & 0.0041 & $1.42[1.10-1.84]$ & 0.0081 \\
\hline Macroarea $^{\mathrm{a}}$ & $0.75[0.67-0.84]$ & $<0.0001$ & $0.86[0.75-0.98]$ & 0.0236 \\
\hline Weight status ${ }^{\mathrm{b}}$ & $0.31[0.26-0.37]$ & $<0.0001$ & $0.29[0.24-0.35]$ & $<0.0001$ \\
\hline Ward (surgical vs. medical) & $0.52[0.41-0.64]$ & $<0.0001$ & $0.60[0.44-0.82]$ & 0.0013 \\
\hline Malignancies & $1.70[1.28-2.25]$ & 0.0002 & $1.63[1.17-2.27]$ & 0.0036 \\
\hline $\operatorname{Drugs}^{c}$ & $1.38[1.19-1.59]$ & $<0.0001$ & $1.22[1.02-1.45]$ & 0.0314 \\
\hline
\end{tabular}

OR odds ratio, $[95 \%$ CI] $95 \%$ confidence interval

* Model further adjusted for specialty

${ }^{a}$ Entered as categorical variable and coded as follows: $0=$ North, $1=$ Centre, $2=$ South, $3=$ Island

bentered as continuous variable; odds ratio calculated according 1 standard deviation increase

'Entered as categorical variable and coded as follows: $0=0-2$ drugs/day, $1=3-5$ drugs/day, $2=6$ or more drugs/day 
ly affect the incidence of malnutrition and nutritional status (general internal medicine, geriatrics, general/abdominal surgery, orthopaedics, oncology, intensive care) $[1,5,11,16]$, while only a few have been designed to be multidisciplinary in a broad sense $[2,9,17,18,28]$ or to provide nationally representative prevalence data $[9$, 16-18]. Thus, the effect of geography-related factors has been scarcely taken into account during data analysis. Up to now, the highest-quality nationwide surveys are the one performed by Wyszynski et al. [18], describing the situation in Argentine hospitals and the "German hospital malnutrition study" by Pirlich et al. [9]. Unfortunately, no attention was paid to geographical factors in relation to possible improvement of nutritional screening procedures. It is in this respect that we believe our study provides additional information and allows recommendations on nutritional policy implementations.

The present results confirm that age, cancer and multiple morbidities are major independent risk factors for malnutrition on hospital admission [1, 5, 9]. Prevalence across specialties are markedly heterogeneous, thus reflecting the different features (e.g., age, disease severity, etc.) of the patients.

In Italy, overall hospital prevalence of malnutrition was $30.7 \%$, with higher rates in those aged 65 years $(34.3 \%$ vs. $27.7 \%)$, in the northern area of the country $(36.7 \%)$ and in Medical Departments $(37.0 \%)$ rather than in Surgical (23.3\%). This was probably related to the fact that patients admitted to Medical Departments were older and so more likely to suffer more severe diseases, comorbidities and malignancies $[1,5,6,9,18]$. These data are also consistent with those of the German study reporting a whole country prevalence of $27.4 \%$ and a similar trend between Medical (33.8\%) and Surgical (13.6\%) Wards [9]. Thus, malnutrition in a surgical setting might appear less frequently than previously reported $[1,11,16]$, but, as suggested, the discrepancy could be mainly explained by the different instruments used to assess nutritional status [9]. However, our diagnostic analytical criteria are more likely to agree with the SGA used in the German survey by Pirlich et al. [9]. Nevertheless, it should be mentioned that our study was designed to include a lower number of elderly patients, as demonstrated by the lower age of our malnourished population compared to the German one $(61.0 \pm 18.6$ years vs. $\sim 1 \pm 15$ years $)$. Accordingly, it is reasonable to argue for a slight underestimation in our survey.

When interpreting the data of our survey, the high number of overweight (37.6\%; BMI $\geq 25 \mathrm{~kg} / \mathrm{m}^{2}$ ) and obese $\left(21.0 \% ; \mathrm{BMI} \geq 30 \mathrm{~kg} / \mathrm{m}^{2}\right)$ patients included is also noteworthy. However, if the prevalence of moderate weight excess is rather comparable to that of the whole country (34.2\%, ISTAT 2005), prevalence of obesity is about twice the expected ratio (9.8\%), particularly in the southern/island area (25.9\% vs. $10.3 \%)$ [26], thus highlighting the importance of this condition in the occurrence of morbidities. Is it possible that this factor might have influenced the estimation of malnutrition? Indeed, this factor masked most of the association between the "geography" and malnutrition. In Europe, similar prevalence data $(51.9 \%)$ have recently been reported by the German study group [8] but the possible effect on prevalence estimation has not been discussed. Overweight is certainly considered a protective factor in people aged over 65 years [29]. Our rates are probably justified by the lower number of elderly patients included rather than by the distribution of overweight described among European countries. On the other hand, a geographical trend in prevalence is reported for Italy and present data strongly agree with this picture [26, 27]. Different diseases might present with a geographical distribution due to genetic/ethnic reasons and the detrimental effect on nutritional status is not homogeneous [1, 5]. Unfortunately, we were not able to analyse this factor but we believe that a larger mass of data is required for this purpose. Alternatively, we can suggest that the slight, but significant, association between malnutrition and "geography" detected by the multivariate model might be explained accordingly. Moreover, we cannot exclude that the accuracy of analytic screening criteria might be affected by both overweight and ethnic factors.

In this regard, we believe that important suggestions to implement nutritional screening policies should be provided. Nowadays, the use of two simplified nutritional screening tools, MUST and NRS-2002, is enforced, particularly when addressing the low dependence on personnel training [4, 5, 22-24]. Unfortunately, these instruments strongly depend on BMI and weight measurement for both BMI calculation and weight loss estimation. In our study, BMI was used for diagnosis in only 107 patients $(22 \%)$ and only in $22(17.8 \%)$ in the southern/island macroarea. In 103 patients $(6.5 \%) \mathrm{BMI}$ was unavailable but malnutrition was detected by alternative criteria in 34 (33\%). Moreover, the availability of all data is needed for the use of both MUST and NRS-2002. In our population, exclusion of patients with missing values for BMI, oral intake and weight loss ( $n=437$ ) would have meant similar rates of malnutrition (32.7\%) but diagnosis would have been missed for 111 patients. On the other hand, the independent relationship between outcomes and also the single components of NRS2002 have been recently associated with outcome [5]. This does not mean that the choice of analytical criteria should be preferred to that of simple and widely applicable validated tools, because the latter (albumin, prealbumin, weight loss and reduced food intake) can account for the effect of disease on nutritional risk only in part [30-33]. Our choice 
was not random and reflects all the efforts that should be made to identify, and so to treat, every patient at risk. Thus, further improvements in screening policies are suggested, particularly when the management of overnourished or not completely assessable patients is considered. Along with this, training and awareness of healthcare professionals should be implemented further. This seems to be in line with the recent reports describing the still poor nutritional attitudes and practices among medical and nursing staff [12-14]. Thus, we cannot ensure that all patients were correctly screened. Moreover, the high rate of refusal (14.6\%) during the recruitment phase should be mentioned. We cannot exclude that sicker patients were more likely to deny their consent probably because of their health status. The choice of hospital with a clinical nutrition unit was also made because of the fact that these are usually the biggest hospital, thus allowing all disciplines to be investigated. However, the prevalence of malnutrition appears remarkably higher in non-university hospitals rather than in the university ones [9]. Thus, further studies are required to provide more precise prevalence data. No rigid stratification by age can be hypothesised and the inclusion of paediatric departments should be also planned, given also the trends in overweight and obesity $[34,35]$.

Finally, we must underscore the importance of collecting nutrition-related outcome indicators, such as length of stay (LOS), death or infectious complications $[1,4-7,9,16,28]$, to better investigate the possible effect of overweight and "geography" factors.

In conclusion, our study confirms the high incidence and prevalence of malnutrition in patients on hospital admission. Along with this, overweight and obesity are widespread conditions as well. Malnutrition might also present with different rates according to demographic and geographical factors. Age, malignancies and multidrug therapy are the strongest risk factors. Nutritional policies in relation to screening and support should be implemented accordingly.

Acknowledgements This study was partially supported by grants of Nutricia (Milan, Italy). We gratefully acknowledge Professors Gianfranco Guarnieri and Gianni Biolo (University of Trieste) for their valuable advice given during the drafting of the manuscript. We are particularly grateful to all the contributing Centres (the PIMAI group) and the relative personnel (nutritional scientists, dieticians and nurses) involved in data collection:

Dietetic and Clinical Nutrition Unit, Regional General Hospital Bolzano: Lucchin L, Lando L, Borgo S, Saffiotti GL.

Dietetic and Clinical Nutrition Unit, "Niguarda-Ca Granda" Hospital, Milano: Gentile MG, Rodeschini E, Sandri LG.

Dietetic and Clinical Nutrition Unit, "Maggiore della Carità" Hospital, Novara: D'Andrea F, Brugnani M, Barbero B, Passera S. Dietetic and Clinical Nutrition Unit, University Hospital, Padova: Caregaro L, Nardi MT.

Dietetic and Clinical Nutrition Unit, "S. Martino" Hospital, Genova: Sukkar GS, Ferrari C.
Dietetic and Clinical Nutrition Unit, "Le Scotte" University Hospital, Siena: Mattei R, Grosso A, Francalanzi C, Cardinali F, Borsi E. Dietetic and Clinical Nutrition Unit, "Casa Sollievo della Sofferenza" Hospital, S. Giovanni Rotondo, Foggia: Orban A, Cianti L.

Endocrinology, Diabetology and Clinical Nutrition Unit, "S. Sebastiano" Hospital, Caserta: Prilli M, Capriello R, Sorrentino S, Pennino MR.

Dietetic and Clinical Nutrition Unit, "Canizzarro" Hospital, Catania: Leonardi F, Bellino AME, Massimino EA.

Dietetic and Clinical Nutrition Unit, "Umberto I" Hospital, Ancona: Nicolai A, Petrelli M, Taus M, Busni D, Borri MG, Vitrini S.

Dietetic and Clinical Nutrition Unit, "A. Cardarelli" Hospital, Campobasso: Pastò S, Di Biase P, D’Onofrio R, Di Brino AM, Celi C, Mastronuzzi V.

Department of Internal Medicine, University "La Sapienza", Roma: Muscaritoli M, Preziosa I, Canali A.

Dietetic and Clinical Nutrition Unit, "S. Maria" Hospital, Terni: Fatati G, Mirri E, Palazzi M, Vendetti AL, Sette S, Panetta V.

National Institute for Research on Food and Nutrition (INRAN), Rome.

Conflict of interest All Authors certify that there are no affiliations with or involvement in any organisation or entity with a direct financial interest in the subject matter or materials discussed in the manuscript.

\section{* L. Lucchin \\ Chief of the coordinating centre \\ Dietetic and Clinical Nutrition Unit \\ Regional General Hospital of Bolzano \\ Via Boehler 5, 39100 Bolzano, Italy}

\section{A. D'Amicis}

National Institute for Research on Food and Nutrition (INRAN) Rome, Italy

\section{M.G. Gentile}

Dietetic and Clinical Nutrition Unit

"Niguarda-Ca Granda" Hospital

Milan, Italy

\section{N.C. Battistini}

Department of Applied Dietetic Technical Sciences

University of Modena and Reggio Emilia

Modena, Italy

\section{M.A. Fusco}

Dietetic and Clinical Nutrition Unit

"S.Camillo-Forlanini" Hospital

Rome, Italy

\section{A. Palmo}

Dietetic and Clinical Nutrition Unit

University Hospital San Giovanni Battista

Turin, Italy

\section{Muscaritoli}

Department of Clinical Medicine

University "La Sapienza"

Rome, Italy

F. Contaldo

Department of Clinical and Experimental Medicine

"Federico II" University

Naples, Italy 


\section{References}

1. Norman K, Pichard C, Lochs H, Pirlich M (2008) Prognostic impact of disease-related malnutrition. Clin Nutr 27:5-15

2. Corish CA, Kennedy NP (2000) Protein-energy undernutrition in hospital in-patients. Br J Nutr 83:575-591

3. Elia M, Zellipour L, Stratton RJ (2005) To screen or not to screen for adult malnutrition? Clin Nutr 24:867-884

4. Kyle UG, Kossovsky MP, Karsegard VL, Pichard C (2006) Comparison of tools for nutritional assessment and screening at hospital admission: a population study. Clin Nutr 25:409-417

5. Sorensen J, Kondrup J, Prokopowicz J et al; EuroOOPS study group (2008) EuroOOPS: an international, multicentre study to implement nutritional risk screening and evaluate clinical outcome. Clin Nutr 27:340-349

6. Cederholm T, Jagren C, Hellstrom K (1995) Outcome of protein energy malnutrition in elderly medical patients. Am J Med 98:67-74

7. Kyle UG, Genton L, Pichard C (2005) Hospital length of stay and nutritional status. Curr Opin Clin Nutr Metab Care 8:397-402

8. Kruizenga HM, Van Tulder MW, Seidell JC et al (2005) Effectiveness and cost-effectiveness of early screening and treatment of malnourished patients. Am J Clin Nutr 82:1082-1089

9. Pirlich M, Schütz T, Norman K et al (2006) The German hospital malnutrition study. Clin Nutr 25:563-572

10. Amaral TF, Matos LC, Tavares MM et al (2007) The economic impact of disease-related malnutrition at hospital admission. Clin Nutr 26:778-784

11. McWhirter JP, Pennington CR (1994) Incidence and recognition of malnutrition in hospital. BMJ 308:945-948

12. Mowe M, Bosaeus I, Rasmussen HH et al (2006) Nutritional routines and attitudes among doctors and nurses in Scandinavia: a questionnaire based survey. Clin Nutr 25:524-532

13. Singh H, Watt K, Veitch R et al (2006) Malnutrition is prevalent in hospitalized medical patients: are housestaff identifying the malnourished patient? Nutrition 22:350-354

14. Bavelaar JW, Otter CD, van Bodegraven AA et al (2008) Diagnosis and treatment of (disease-related) in-hospital malnutrition: the performance of medical and nursing staff. Clin Nutr 27:431-438

15. Beck AM, Balknäs UN, Camilo ME et al; hoc group on Nutrition Programmes in Hospitals, Council of Europe (2002) Practices in relation to nutritional care and support: report from the Council of Europe. Clin Nutr 21:351-354

16. Rasmussen HH, Kondrup J, Staun M et al (2004) Prevalence of patients at nutritional risk in Danish hospitals. Clin Nutr 23:1009-1015

17. Waitzberg DL, Caiaffa WT, Correia MI (2001) Hospital malnutrition: the Brazilian national survey (IBRANUTRI): a study of 4000 patients. Nutrition 17:573-580
18. Wyszynski DF, Perman M, Crivelli A (2003) Prevalence of hospital malnutrition in Argentina: preliminary results of a populationbased study. Nutrition 19:115-119

19. Correia MI, Campos AC (2003) Prevalence of hospital malnutrition in Latin America: the multicenter ELAN study. Nutrition 19:823-825

20. Comi D, Palmo A, Brugnani M et al (1998) The hospital malnutrition Italian study. Clin Nutr 17[Suppl 1]:52 (Abstract)

21. Bedogni G, Borghi A, Battistini NC (2001) Manuale di valutazione antropometrica dello stato di nutrizione. EDRA Medical Publishing \& New Media, Milan

22. Kondrup J, Allison SP, Elia M et al; Educational and Clinical Practice Committee, European Society of Parenteral and Enteral Nutrition (ESPEN) (2003) ESPEN guidelines for nutrition screening 2002. Clin Nutr 22:415-421

23. Lean M, Wiseman M (2008) Malnutrition in hospitals. BMJ 336:290

24. Barendregt K, Soeters PB, Allison SP, Kondrup J (2008) Basic concepts in nutrition: diagnosis of malnutrition - screening and assessment. e-SPEN Eur e-J Clin Nutr Metab 3:e121-e125

25. Planas M, Audivert S, Pérez-Portabella C et al (2004) Nutritional status among adult patients admitted to an university-affiliated hospital in Spain at the time of genoma. Clin Nutr 23:1016-1024

26. Mappe, Popolazione, Statistiche Demografiche dell'Istituto Nazionale di Statistica. Accessed 1 May 2008, at http://demo.istat.it/

27. Calza S, Decarli A, Ferraroni M (2008) Obesity and prevalence of chronic diseases in the 1999-2000 Italian National Health Survey. BMC Public Health 8:140

28. Edington J, Boorman J, Durrant ER et al (2000) Prevalence of malnutrition on admission to four hospitals in England. The Malnutrition Prevalence Group. Clin Nutr 19:191-195

29. Heiat A, Vaccarino V, Krumholz HM (2001) An evidence-based assessment of federal guidelines for overweight and obesity as they apply to elderly persons. Arch Intern Med 161:1194-1203

30. Seltzer MH, Bastidas JA, Cooper DM et al (1979) Instant nutritional assessment. JPEN J Parenter Enteral Nutr 3:157-159

31. Robinson MK, Trujillo EB, Mogensen KM et al (2003) Improving nutritional screening of hospitalized patients: the role of prealbumin. JPEN J Parenter Enteral Nutr 27:389-395

32. Lankisch P, Gerzmann M, Gerzmann JF, Lehnick D (2001) Unintentional weight loss: diagnosis and prognosis. The first prospective follow-up study from a secondary referral centre. J Intern Med 249:41-46

33. Kagansky N, Berner Y, Koren-Morag N et al (2005) Poor nutritional habits are predictors of poor outcome in very old hospitalised patients. Am J Clin Nutr 82:784-791

34. Pawellek I, Dokoupil K, Koletzko B (2008) Prevalence of malnutrition in paediatric hospital patients. Clin Nutr 27:72-76

35. Tanne $\mathrm{J}$ (2006) No progress in reducing childhood obesity despite increased awareness, report says. BMJ 333:620 